\title{
EVIDENCE OF HUMAN INTER-TISSUE BIOELECTROMAGNETIC TRANSFER: THE HUMAN BLOOD TISSUE INTRINSIC BIOELECTROMAGNETIC ENERGY TRANSFERRING ONTO A MINIORGAN
}

\author{
Abrahám A. Embí BS MBA *1⁄ iD \\ *11 13442 SW 102 Lane, Miami Florida, USA 33186
}

DOI: https://doi.org/10.29121/granthaalayah.v8.i8.2020.1178

Article Type: Research Article

Article Citation: Abrahám A. Embí BS MBA. (2020). EVIDENCE OF HUMAN INTER-TISSUE BIOELECTROMAGNETIC TRANSFER: THE HUMAN BLOOD TISSUE INTRINSIC BIOELECTROMAGNETIC ENERGY TRANSFERRING ONTO A MINIORGAN. International Journal of Research -GRANTHAALAYAH, 8(8), 288-296.

https://doi.org/10.29121/granthaa layah.v8.i8.2020.1178

Received Date: 16 August 2020

Accepted Date: 31 August 2020

Keywords:

Human Blood Bioelectromagmetism

Human Follicle

Bioelectromagnetism

Inter Tissue Bioelectromagnetic

Energy Transfer

Body Parts Energy Exchange

Electromagnetic Radiation

Absortion

Potassium Ferricyanide

Anisotropic Crystal

\section{ABSTRACT}

Basically, the human hair consists of a follicle a.k.a root penetrating the skin and an outer skin structure commonly called the shaft. The hair follicle has been classified as a miniorgan having its own cells divisions; aging stages and also demonstrated to emit electromagnetic radiation. The intent of this manuscript is to demonstrate via in vitro experiments evidence of human inter-tissue electromagnetic energy transfer through a glass slide, namely from human blood tissue to the previously described miniorgan or follicle.

The mechanism behind this new finding was possible due to the introduction in 2015 of a tabletop optical microscopy method designed to display plants and animal tissue electromagnetic energy emissions. Essential to present finding is the described property of anisotropic crystals of full absorption of incoming electromagnetic radiation waves. $\mathrm{K} 3 \mathrm{Fe}$ is an anisotropic crystal. For example, a single layer human blood smear was sandwiched (SDW) by a second glass slide. On the top slide of the SDW, a freshly plucked in toto human hair was then covered by drops diluted K3Fe. Control experiments had repeatedly shown orderly semicircular periodic crystals of K3Fe triggered by the electromagnetic waves emitted by the hair follicle. Prior experiments by this author, have hinted at a "bioelectromagnetic cross-talk" between the follicle and blood. This was seen when there was physical contact between the follicle and blood drops on a glass slide. In the present experiments there is no direct tissue contact, the energy is transmitted through a $1 \mathrm{~mm}$ glass barrier. The data herein presented introduces Bioelectromagnetic Fields (BEMFs) energy from human blood onto a miniorgan. This energy is shown penetrating a $1 \mathrm{~mm}$ glass slide barrier. Further research is warranted to assess the physiological implications of the human blood tissue as a molecular and BEMFs energy source.

\section{Glossary}

SSP: The Single Slide Preparation (SSP) is an open-air technique where freshly plucked in toto scalp hairs were placed on a clean $25 \times 75 \times 1 \mathrm{~mm}$ glass slide; and covered by a drop of K3Fe in solution

SDW: The Sandwich (SDW) entails material trapped between 2 identical glass slides.

(C) 2020 The Author(s). This is an open access article distributed under the terms of the Creative Commons Attribution License, which permits unrestricted use, distribution, and reproduction in any medium, provided the original author and source are credited. 
K3Fe: Acronym Potassium FerrIcyanide Crystal formula. $\quad$ K3Fe (CN)6.CSA \# 13746-66-2.

BEMFs: Acronym for Bioelectromagnetic Fields. Bioelectromagnetics, also known as bioelectromagnetism, is the study of the interaction between electromagnetic fields and biological entities.

\section{INTRODUCTION}

The purpose of this manuscript is to introduce documentation demonstrating the transfer of BEMFs energy from human connective tissue (blood) to a human mini-organ (hair follicle). The hair follicle has been classified as a miniorgan, thus exhibiting its own cells division molecular activity and metabolism [1]. The Bioelectromagnetic discipline was first documented by using a sensitive atomic magnetometer detecting BEMFs in living tissue [2]; and documented by using complex equipment [3]. In this manuscript a tabletop glass slide microscopy method introduced in 2015, has enabled for the documentation of BEMFs in plants and animal tissue [4], [5]; and expanded BEMFs experimentation with minimal equipment requirements. One paper in particular has relevancy to this manuscript and is the demonstration of hair follicles BEMFs penetrating glass barriers [6].

\subsection{EVIDENCE OF BEMFS TRANSFER BETWEEN BLOOD AND AN ORGAN}

In this manuscript, In Vitro experiments using optical microscopy will introduce evidence of BEMFs transfer between blood and hair follicles through a glass barrier. Results from in vitro experiments where a 1 mm glass slide barrier vertically separating blood and hair follicle will show evidence of BEMFs energy transfer between two tissues resulting in an increase in crystallization surrounding the follicle.

\section{MATERIALS AND METHODS}

\subsection{MATERIALS}

1) Potassium FerrIcyanide Crystal. $\mathrm{K}_{3} \mathrm{Fe}(\mathrm{CN})_{6}$. CSA \# 13746-66-2.

2) Human Blood Smear

3) Hair Follicles plucked via tweezers from author's scalp

4) Microscope glass slides: 25x75x1mm thickness. Pearl Cat. No. 7101

5) Water purity confirmed by hand held electrical fields detector manufactured by Lishtot Detection LTD, Israel. For details link to: https://www.lishtot.com/TDP1.html

6) Room relative humidity monitored by an ACU-RITE sensor model \# 01536-RX.

7) Digital Video Microscope Celestron II model \# 44341, California, USA.

8) Images downloaded to an Apple Computer MacBook Pro Photo Application.

\subsection{METHODS}

\subsubsection{PREPARING THE SOLUTION}

Commercially available bottled water was tested for impurities via a handheld electrical fields sensor (Lishtot Sensor). A solution was prepared by diluting $\cong 2$ grams of Potassium Ferricyanide $\left(\mathrm{K} \mathrm{Fe}_{3}\right)$ in 2 ml of the previously tested for impurities bottled spring water. The solution placed inside a 6 inch $4 \mathrm{~mm}$ OD glass tube and withdrawn as needed via pipette.

\subsubsection{THE SINGLE SIDE PREPARATION (SSP)}

The SSP is an open-air technique where freshly plucked in toto scalp hairs were placed on a clean $25 \times 75 \times 1 \mathrm{~mm}$ glass slide; and covered by a drop of K3Fe in solution; the drop was then allowed to evaporate. Prior to evaporation, the drop was then touched by a wooden toothpick and scattered as to cover the follicle and shaft (Fig 1). 
After the hair sample in SSP is stabilized, meaning the hair sample can be moved and stay in place. A wooden toothpick us used to gently find an optimal position of the samples such as away from the drops edges.

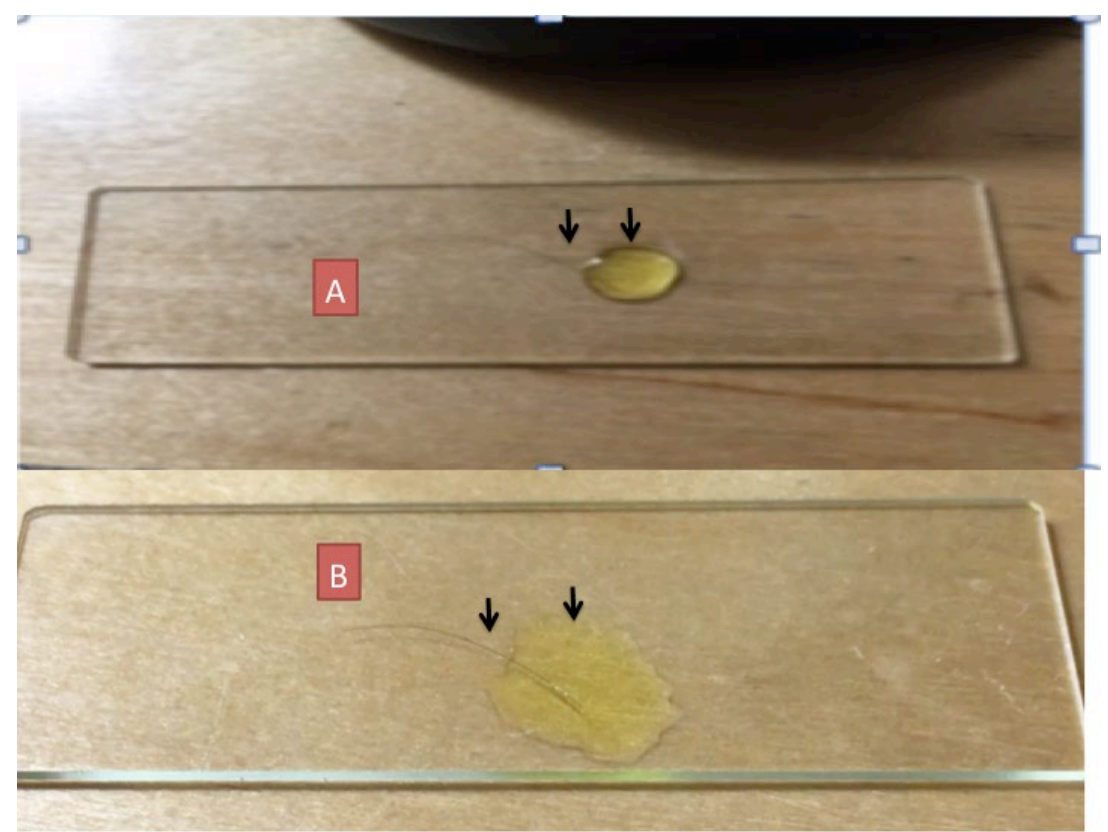

Figure 1 A: Scalp hair on glass slide covered by drop of $\mathrm{KFe}_{3}$ (Potassium Ferricyanide) covering mainly the hair follicle. B: Same hair. Now the $\mathrm{KFe}_{3}$ drop surface tension disturbed and fluid scattered via wooden toothpick now covering follicle and shaft.

\section{The Sandwiched Blood Smear (SDW) Preparation}

A finger stick allowed for the milking of two drops of blood, then placed on a clean $25 \times 75 \times 1 \mathrm{~mm}$ glass slide. The mechanical smear was done as per published instructions from the USA center for disease control [7]. The smear was allowed to dry by keeping it uncovered and at room temperature for 5 minutes. The SSP slide (Fig 2) was then placed over the dry blood smear, thus creating a human blood SDW. The preparation was then allowed to evaporate in the dark by covering with one half of an empty microscope slide box. The average time for total evaporation is two hours, after which was placed on the video microscope-viewing field. Microphotographs and video recordings were obtained and downloaded into an Apple MacBook Pro computer Photo Application for further review.

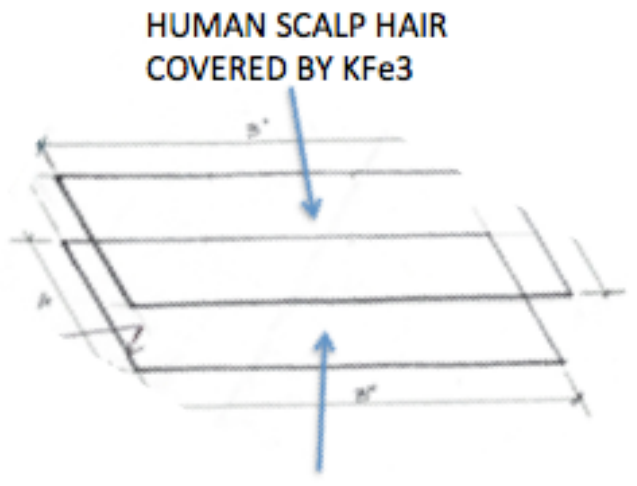

HUMAN BLOOD SMEAR

Figure 2: Slide assembly showing the human blood smear placement sandwiched (SDW) between two $1 \mathrm{~mm}$ thick glass slides. The human hair is placed on the top slide and covered by diluted crystals of Potassium

Ferricyanide (K3Fe). 


\section{RESULTS}

\subsection{EXTERNAL BEMFS ON CRYSTALLIZATION ADVANCE}

The In Vitro experiments (n 12) of sandwiched (SDW) blood tissue showed several phenomena that could be contrasted with control experiments (n 25) as shown (Fig 3) below.

\subsubsection{CONTROL EXPERIMENT WITHOUT BLOOD SMEAR}

Figure below showing a control (No Blood smear in SDW) follicle in SSP K3Fe. The organized periodic BEMFs expressed as semicircular K3Fe crystals in front of the follicles can be appreciated (Fig 3) below.

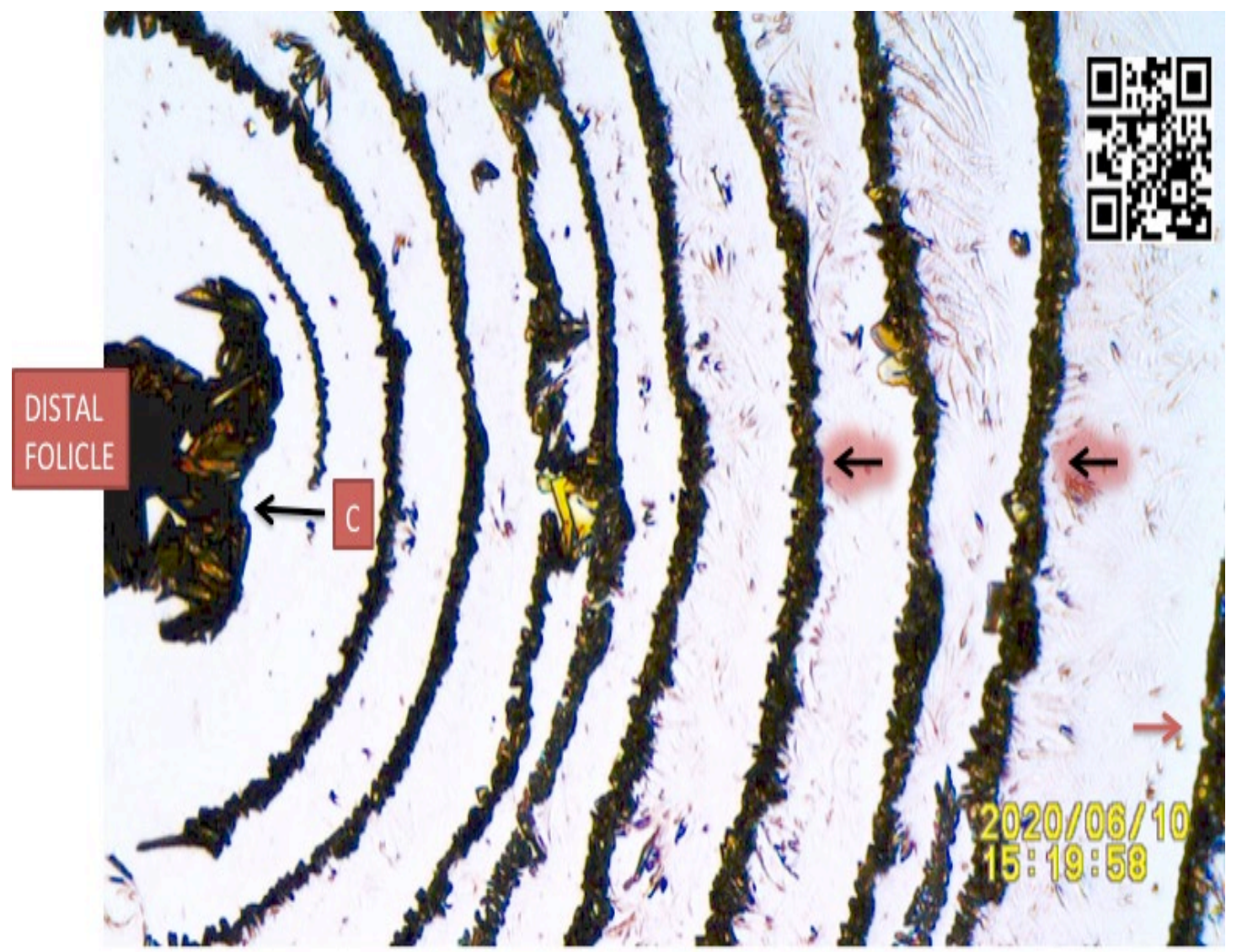

Figure 3: Control scalp hair SSP K3Fe. No blood SDW at $1 \mathrm{~mm}$ distance- showing crystallized undisturbed periodic BEMFs waves from the hair follicle. $\mathrm{C}=$ Arrow pointing at paramagnetic Ferricyanide crystallization in front of Dermal Papilla area. Highlighted black arrows: Pointing at K3Fe crystals delineating the usual hair follicle

BEMFs waves. Small Red Arrow: (Bottom right) Pointing at hair follicle BEMFs reach as expressed by a last semicircular crystallization pattern. For additional details link to: https://youtu.be/o1u5mHopdeo Or Scan QR Code in right upper corner of figure.

\subsubsection{EXPERIMENTS WITH SMEARED BLOOD TISSUE IN SDW}

In the slide preparation below, the hair follicle emitted BEMFs have not yet being sensed by the $\mathrm{KFe}_{3}$ crystals (Fig 4). Notice the lack of delay in the crystallization advance during evaporation. 
Evidence of Human Inter-Tissue Bioelectromagnetic Transfer: The Human Blood Tissue Intrinsic Bioelectromagnetic Energy Transferring onto A Miniorgan

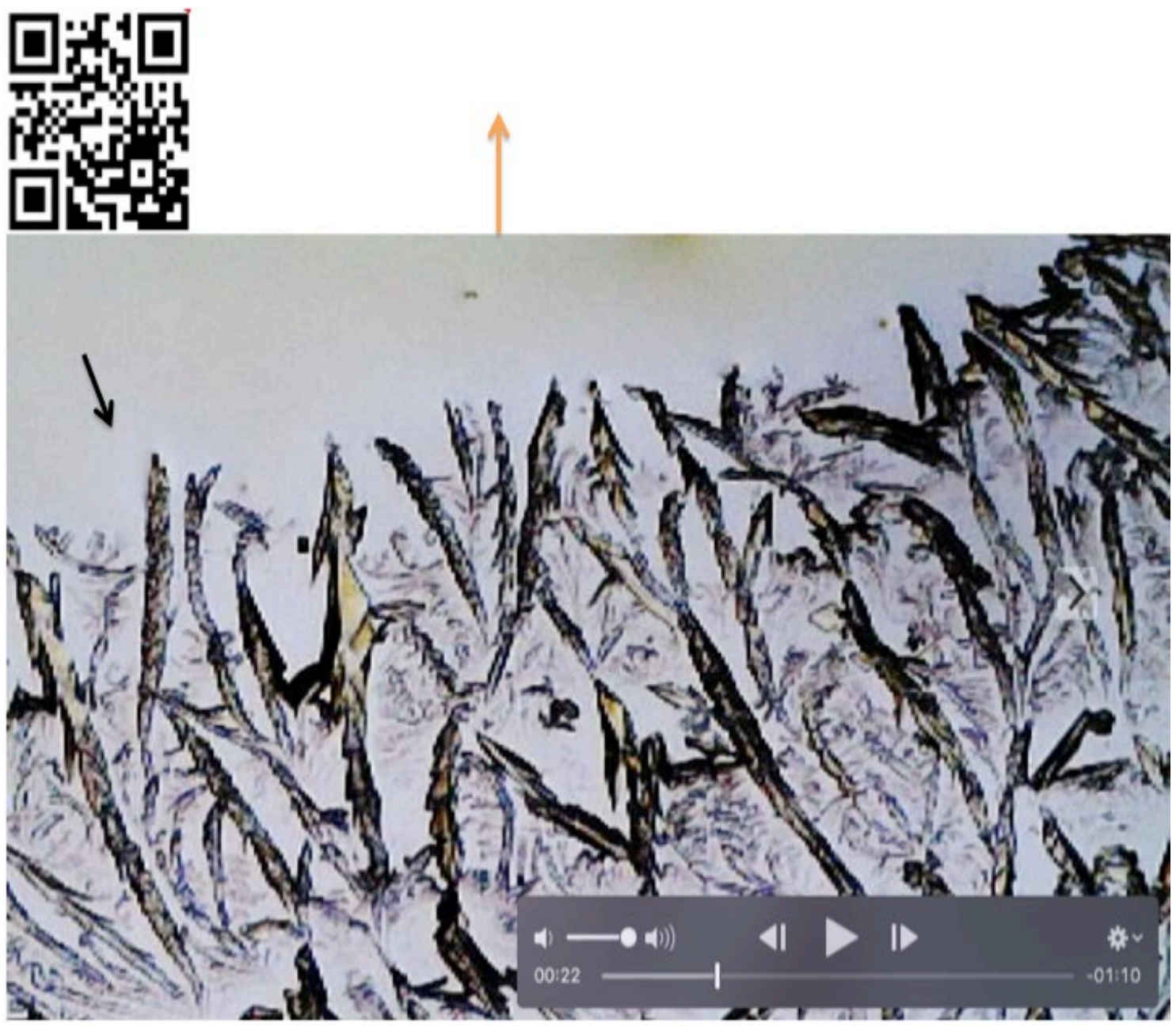

Figure 4: Showing unimpeded crystallization advance of Potassium Ferricyanide in solution (K3Fe). Black Arrow: Pointing at advancing crystallization. This is an example of contrasting crystallization transit times, not influenced first; and then influenced by hair external BEMFs as seen in Figure 5 below. Orange Arrow: Showing position of unseen hair follicle. Please note in video after 00:22" into the evaporation, the hair follicle's BEMFs reach begins to delay the advance.

For additional details link to URL https://youtu.be/h40EYgLn9Ic.....or Scan QR Code in upper left corner of image.

\subsubsection{ENTERING THE OUTER EDGE OF FOLICLE BEMFS AND FULL ABSORPTION BY K3FE CRYSTALS}

Once that threshold is entered the effect seen could be described as a temporary slowing of evaporation advance by the hair follicle intrinsic BEMFs on the evaporating K3Fe (Fig 5). Prior papers support full absorption of BEMFs by the anisotropic K3Fe crystals [8], [9]. As stated in the periodical Science Daily "Moscow Institute of Physics and Technology. (2016, January 14). New way to absorb electromagnetic radiation demonstrated: Scientists show that it is possible to fully absorb electromagnetic radiation using an anisotropic crystal. ScienceDaily. Retrieved August 28, 2020 www.sciencedaily.com/releases/2016/01/160114113524.htm

This is documented in Figure 5 below, where once the BEMFs boundary of the hair follicle there are back and forth forces at play, thus delaying the crystallization advance. 


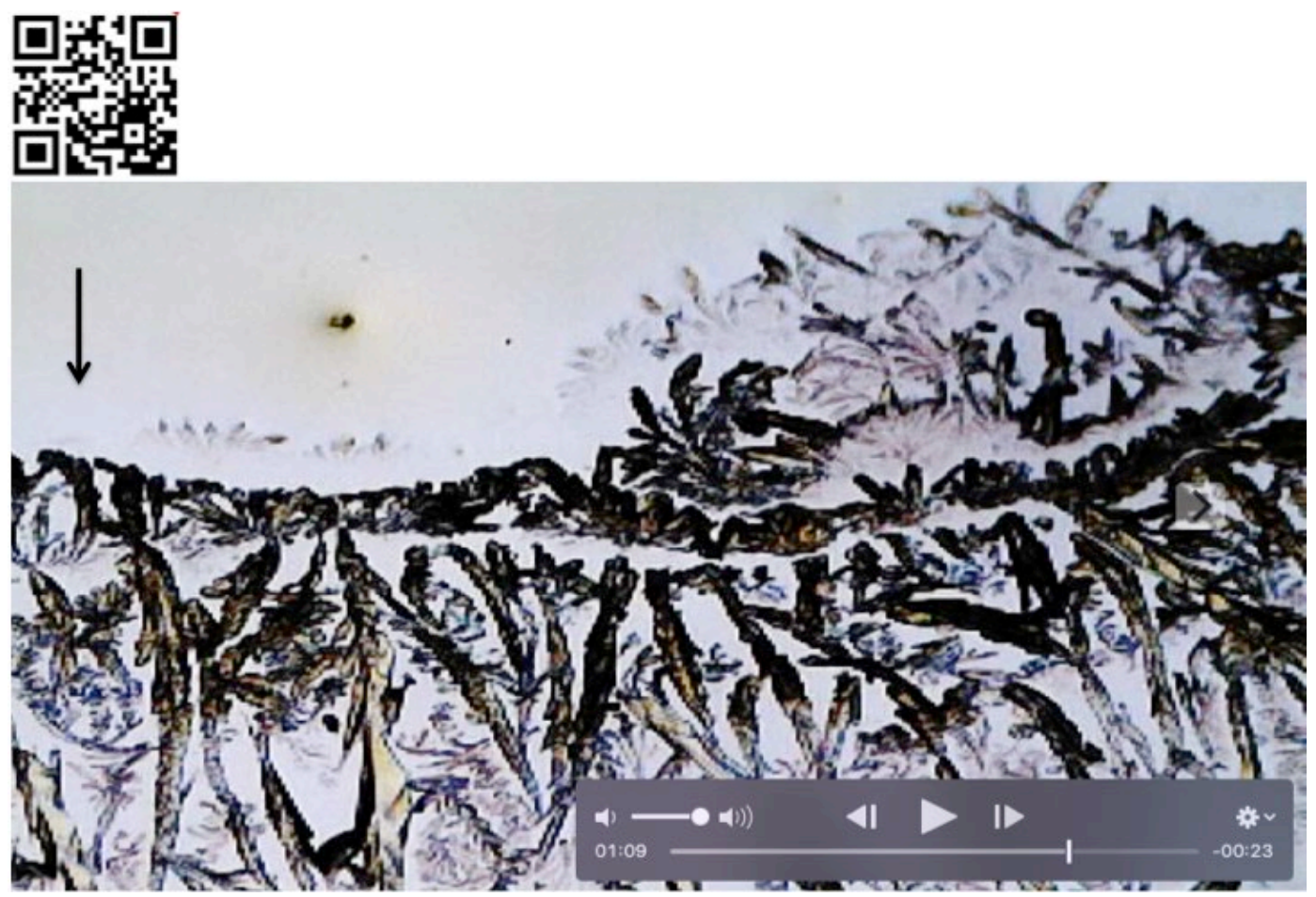

Figure 5: This image shows the slowing on crystallization advance of $\mathrm{KFe}_{3}$ crystals due to K3Fe now absorbing the hair BEMFs. Black Arrow: Pointing at thickening of crystallization line. For additional details link to URL

https://youtu.be/h40EYgLn9Ic.....or Scan QR Code in upper left corner of image. Video frame at 01:08”

\subsubsection{ADDITIONAL EXPERIMENTS CONFIRMING EFFECT OF BEMFS BEING ABSORBED BY K3Fe}

Again, in this manuscript once the $\mathrm{KFe}_{3}$ in solution had completely evaporated, there is an increase in crystals adhering to the hair follicles as shown in the following examples (Fig 6,7,8,9). This caused by the blood tissue transferring BEMFs energy through a $1 \mathrm{~mm}$ glass slide and absorbed by K3Fe crystals.

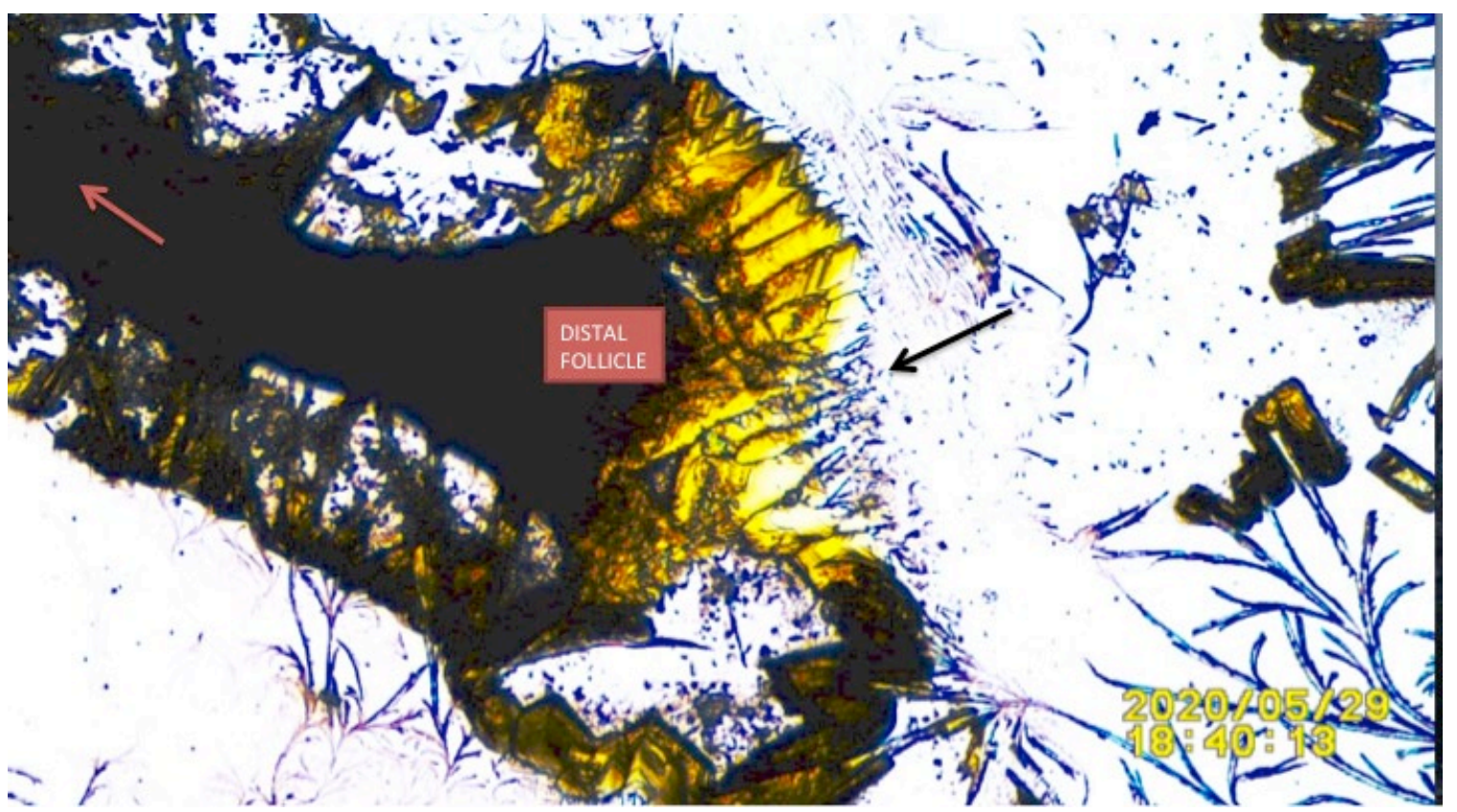

Figure 6: Human hair in SSP K3Fe under the effect of Blood SDW- Black Arrow: Pointing at heavy crystallization of paramagnetic K3Fe surrounding the follicle. Red Arrow: In upper left side of image pointing towards the hair shaft. 


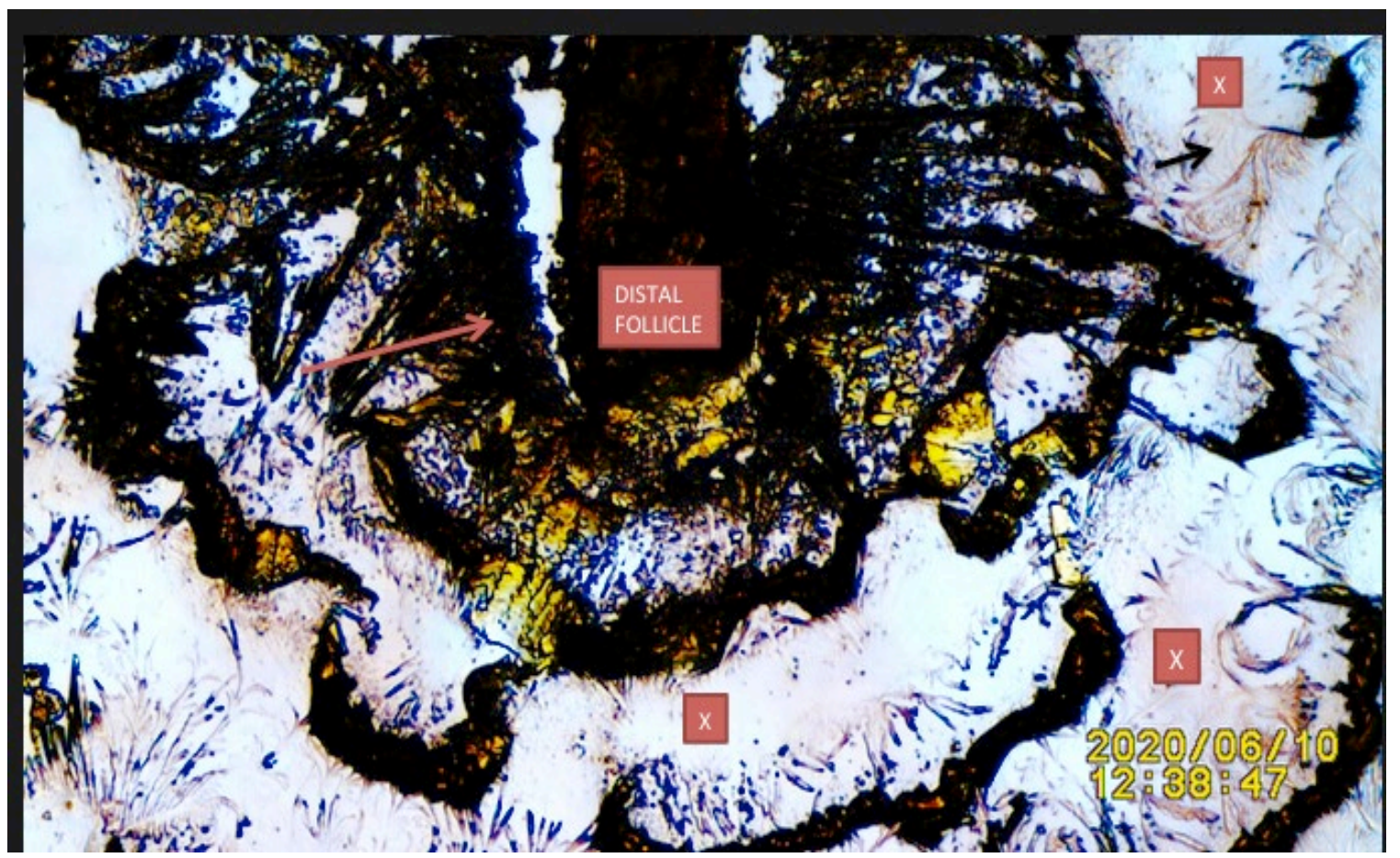

Figure 7: Hair follicle post K3Fe evaporation showing the effect of blood BEMFs. Notice accumulation of crystals surrounding follicle.

Red Arrow: Pointing at KFe3 crystals surrounding follicle. X and Black Arrow: Pointing at red shadows from blood smear in SDW.

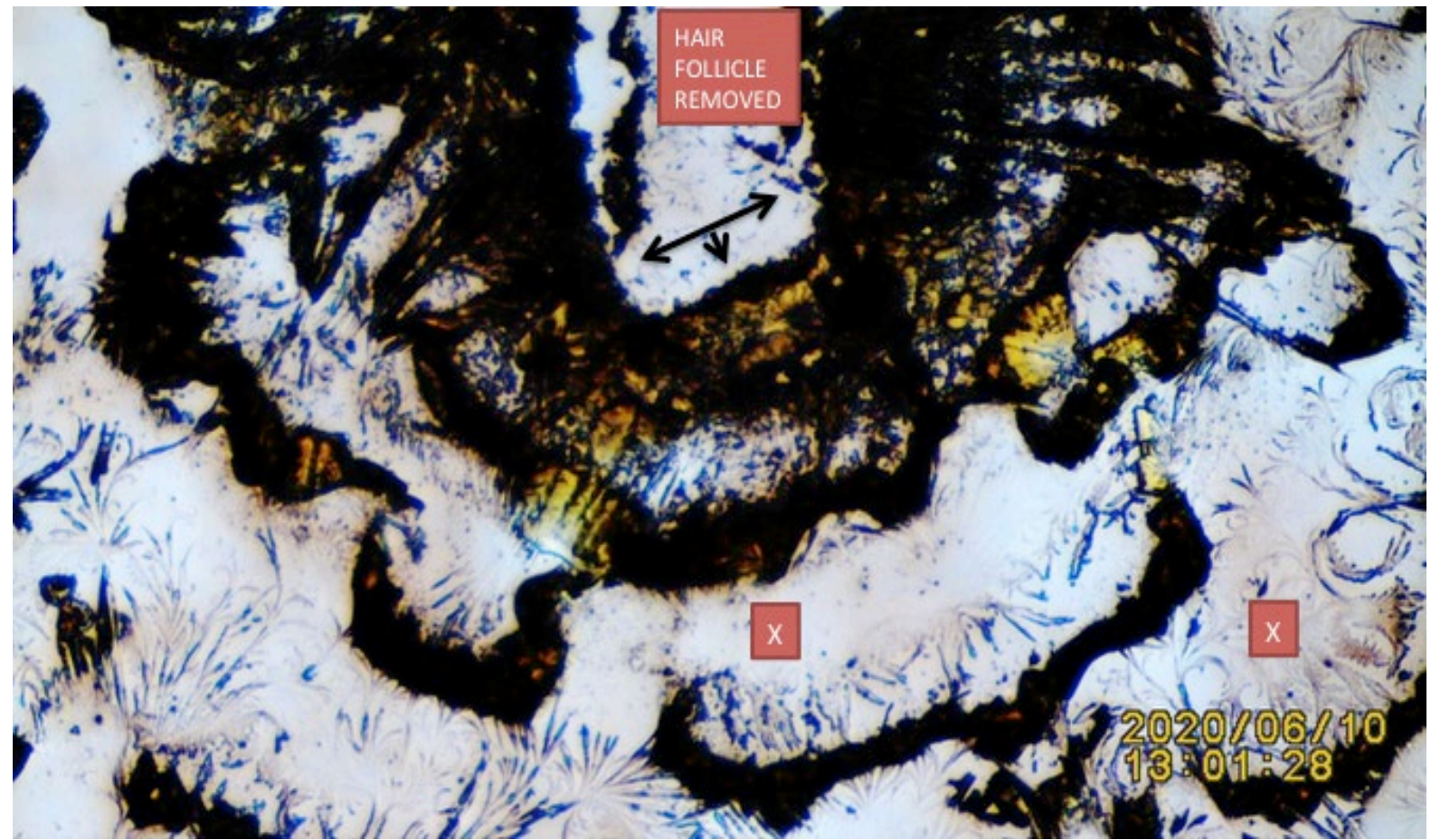

Figure 8: Same hair as in Figure 7 above. Hair follicle post K3Fe evaporation showing effect of blood BEMFs. The hair follicle now physically removed via toothpick. Black Arrows: Now pointing at K3Fe crystals surrounding the hair follicle imprint. There is noticeable disruption of the concentric semicircular crystallization as seen in Fig. 3 above. Notice accumulation of crystals surrounding follicle. X: Notice red shadows from the blood smear in SDW. 


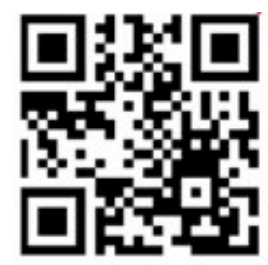

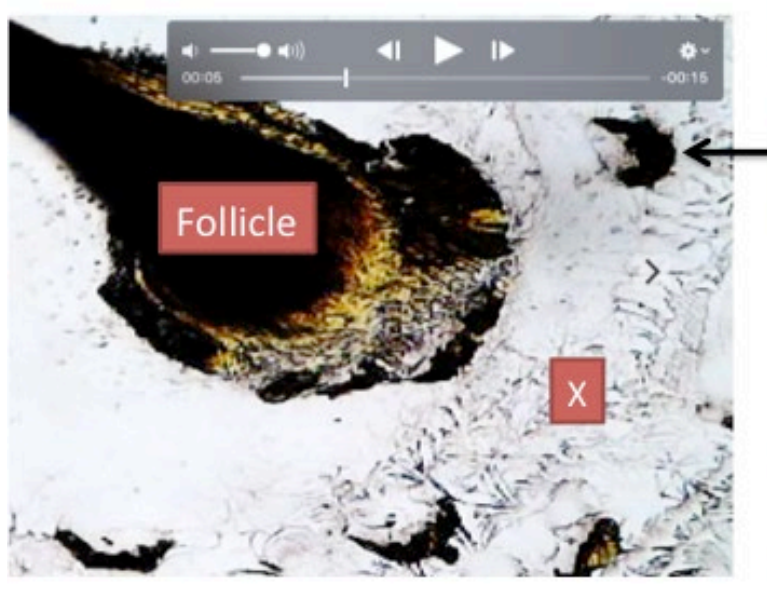

Video Frame 00:03"

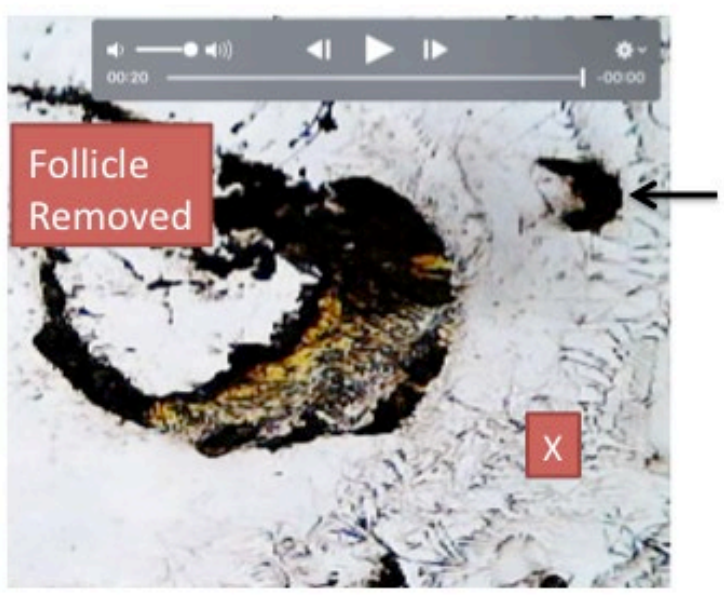

Video Frame

00:20"

Figure 9: Composite slide of another experiment showing selected video frames pre and post hair follicle removal. Showing effect of blood tissue on a hair follicle inherent biomagnetic wave. The blood tissue trapped in SDW disturbing crystallization of Potassium Ferricyanide. X: Area void of the normal concentric crystallization of K3Fe caused by electromagnetism. Please compare with Figure 3 above.

For additional details, please visit URL: https://youtu.be/c3o3gliFvqs Or scan QR Code in top right corner of figure.

\section{DISCUSSION}

\subsection{PRIOR DEMONSTRATION OF HAIR FOLLICLE BIOLECTROMAGNETISM DELAYING CRYSTALLIZATION}

As stated in the present manuscript human blood BEMFs are postulated to cause a delay in the transit time of K3Fe crystallyzation. Is important to mention that the human follicle BEMFs had been previosly shown to delay K3Fe crystallization advance [10]. This is the first time that BEMFs penetrating a $1 \mathrm{~mm}$ glass barrier is seen disturbing a hair follicle inherent BEMFs.

\subsection{DEMONSTRATION OF THE EFFECT OF HUMAN BLOOD BEMFS ON HAIR FOLLICLE METABOLISM}

The intrinsic biomagnetism of organs such as the brain and heart have been found to emit bioelectrical signals that could presently be displayed by instrumentation. This manuscript is introducing documentation of human connective tissue (blood) transferring its BEMFs energy onto a human miniorgan (hair follicle). The follicles tested were freshly plucked via tweezers. It has been established that "Although the plucked hair shaft is clearly inferior in cellular quantity and complexity to an intact hair follicle as obtained by a biopsy, it does carry sufficient cellular mass to permit detailed scientific investigations" [11]. 
Evidence of Human Inter-Tissue Bioelectromagnetic Transfer: The Human Blood Tissue Intrinsic Bioelectromagnetic Energy Transferring onto A Miniorgan

\section{SUMMARY AND CONCLUSSIONS}

Scientists have found that anisotropic crystals such as Potassium Ferricyanide (K3Fe) fully absorb incoming electromagnetic radiation. Experiments herein presented confirm a human miniorgan tissue (hair follicle) when surrounded by K3Fe fully absorbs the electromagnetic radiation externally emitted by a connective tissue (blood) through a $1 \mathrm{~mm}$ glass barrier. This inter tissue energy transfer could aid in the understanding genesis of diseases. For example, could human blood pooling in body cavity transfer energy to surrounding tissue and triggering calcification? What are the physiological implications of the newly introduced dual blood tissue energy transfer mechanism in organs?

Further research is warranted.

\section{SOURCES OF FUNDING}

This research received no specific grant from any funding agency in the public, commercial, or not-for-profit sectors.

\section{CONFLICT OF INTEREST}

The author have declared that no competing interests exist.

\section{ACKNOWLEDGMENT}

None.

\section{REFERENCES}

[1] Schneider, M. R., Schmidt-Ullrich, R., \& Paus, R. (2009). The hair follicle as a dynamic miniorgan. Current biology: CB, 19(3), R132-R142. https://doi.org/10.1016/j.cub.2008.12.005

[2] Malmivuo, Jaakko; Robert Plonsey (1994) Bioelectromagnetism: principles and applications of bioelectric and biomagnetic fields. New York: Oxford University Press. (1994) ISBN 978-0195058239.

[3] Corsini E, Acosta V, Baddour N, Higbe J, Lester B, Licht P, Patton B, Prouty M, Budker D. (2011) Search for plant biomagnetism with a sensitive atomic magnetometer.J Appl Physics. 109: 07470-1-5

[4] Scherlag BJ, Huang B, Zhang L, Sahoo K, Towner R, Smith N, Embi AA, Po SS. Imaging the Electromagnetic Field of Plants (Vigna radiata) Using Iron Particles: Qualitative and quantitative correlates. Journal of nature and Science; (2015) 1: e61.

[5] Embi AA, Jacobson JI, Sahoo K, BJ. (2015). Demonstration of Inherent Electromagnetic Energy Emanating from Isolated Human Hairs. Journal of Nature and Science. Jan 1(3): e55.

[6] Embi, AA, Scherlag BJ. Demonstration of Human Hair Follicle Biomagnetic Penetration Through Glass Barriers. International Journal of materials Chemistry and Physics. (2016) Vol 2, No 2, 71-74.

[7] Center for Disease Control. USA. Suggested technique for Blood Smear. https://www.cdc.gov/dpdx/resources/pdf/benchAids/malaria/Malaria_procedures_benchaid.pdf.

[8] D. G. Baranov, J. H. Edgar, Tim Hoffman, Nabil Bassim, Joshua D. Caldwell. (2015) Perfect interferenceless absorption at infrared frequencies by a van der Waals crystal. Physical Review B, 2015; 92 (20) DOI: 10.1103/PhysRevB.92.201405

[9] B. N. Figgis, Malcolm Gerloch, Ronald Mason, and Ronald Sydney Nyholm (1969) The crystallography and paramagnetic anisotropy of potassium ferricyanide. https://doi.org/10.1098/rspa.1969.0031

[10] Abraham A. Embi Bs. (2018). "THE HUMAN HAIR FOLLICLE PULSATING BIOMAGNETIC FIELD REACH AS MEASURED BY CRYSTALS ACCRETION." International Journal of Research - Granthaalayah, 6, 290-299.

[11] Schembri, K., Scerri, C., \& Ayers, D. (2013) Plucked Human Hair Shafts and boiomolecular medical research. The Scientific World Journal, https://doi.org/10.1155/2013/620531 